\title{
UM ESTUDO DE CASO SOBRE A OPINIÃO DOS CLIENTES EM RELAÇÃO AO ATENDIMENTO E AS CONDIÇÕES AMBIENTAIS DE UMA AGÊNCIA BANCARIA NA CIDADE DE PARNAIBA-PI
}

\section{A CASE STUDY ON CUSTOMER'S OPINION ON CARE AND THE ENVIRONMENTAL CONDITIONS OF A BANKING AGENCY IN PARNAIBA-PI}

Edson Medeiros Rodrigues Netto ${ }^{1}$

RESUMO: A imagem criada, através de um estudo de caso, da opinião dos clientes, relacionada ao atendimento dos caixas da agência bancaria da cidade de Parnaíba-PI. No mercado, para enfrentar a concorrência com vantagem, é condição preponderante, até mesmo pela sobrevivência de uma empresa, um atendimento de qualidade, diferenciado. O cliente é atraído pela qualidade do serviço prestado, quando percebe um tratamento adequado e respeitoso, quando sente empatia e segurança no atendimento. Pretende-se, com base nas análises dos resultados de pesquisa, imprimir ações para melhorar o atendimento, qualificando-o, e com isto garantir satisfação plena e fidelidade do cliente aos produtos e serviços oferecidos pela empresa. As pesquisas foram elaboradas para 50 clientes, com finalidade de averiguar, como estão sendo atendidas no setor caixa e qual melhoria deve ser implantada. O resultado obtido são $90 \%$ de descontentes, que sugerem um terceiro caixa devido ao tempo de espera e $10 \%$ sugerem a mesma coisa apenas para os dias de pico e cadeiras devido ao cansaço. Quanto ao tratamento pessoal de cada caixa consideravam regulares. Conclui-se que o nível de satisfação dos clientes relativo ao atendimento dos caixas é ruim. Diante disto, deve-se implementar ações para reverter este resultado para bom ou ótimo e monitorá-lo para, após a alteração, manter-se neste patamar aceitável, e com isto garantir a fidelidade do cliente.

PALAVRAS-CHAVE: Cliente. Serviço de atendimento de caixa. Satisfação do cliente.

ABSTRACT: The image created, through a case study, the opinion of customers, related to the service of bank tellers of the city of Parnaiba-PI. In the market, to face the competition with advantage, is a preponderant condition, even for the survival of a company, a quality service, differentiated. The client is attracted by the quality of the service provided, when they perceive appropriate and respectful treatment, when they feel empathy and security in care. Based on the analysis of the research results, it is intended to print actions to improve the service, qualifying it, and thereby ensuring full satisfaction and customer loyalty to the products and services offered by the company. The surveys were designed for 50 clients to find out how they are being served in the cash sector and what improvement should be implemented. The result is $90 \%$ discontented, suggesting a third box due to waiting time and 10\% suggesting the same thing only for peak days and chairs due to tiredness. Regarding the personal treatment of each cashier they considered regular. It is concluded

\footnotetext{
Bacharel em ADMINISTRAÇÃO (2006). Especialista em Docência do Ensino Superior (2008). Especialista em Gestão de Negócios (2010). Especialista em Marketing (2017). Mestrando em Direção Estratégica de Marketing (2016-2018). Discente do curso de Gestão Hospitalar pela UNINASSAU. Professor do curso de Administração da Faculdade Mauricio de Nassau. Servidor público do Estado do Piauí lotado na Secretaria de Saúde do Piauí - SESAPI
} 
that the level of customer satisfaction regarding cashier service is poor. Given this, actions should be taken to revert this result to good or optimal and monitor it to, after the change, remain at this acceptable level, thereby ensuring customer loyalty.

KEYWORDS: Customer. Cashier Service. Customer Satisfaction.

\section{INTRODUÇÃO}

É comum escutarmos a expressão "o cliente é rei" na maioria das empresas em nosso país, pois essa expressão é assimilada com uma prestação de serviço eficiente e compatível com as necessidades e demandas disponibilizadas pelos clientes, por outro lado a cortesia não sustentará por muito tempo um serviço sem qualidade.

Foi a partir da década de 90, quando houve a abertura do mercado brasileiro. O cliente passou a ser alvo de atenção e de grande importância para a sobrevivência de uma organização empresarial e por parte do cliente aumentou o seu nível de exigência. Como diz Las Casas (1999, p. 43), "As empresas devem priorizar as pesquisas aos clientes e buscar suas expectativas e seu nível de satisfação". A partir deste conhecimento as empresas começaram a utilizar a prática constante de qualificar todo seu corpo funcional através de treinamentos em programas comportamentais e atualizações tecnológicas, favorecendo em extremo a oportunidade de uma organização prosperar em meio a um mercado tão competitivo. Conforme conceitua cliente Chiavenato (2000 p.82), fala que "são os elementos que compram ou adquirem os produtos ou serviços, ou seja, absorvem as saídas e os resultados da organização".

Com passar dos anos, transformações ocorreram e os Bancos não poderiam deixar de acompanhar as mudanças no comportamento econômico do país e a forma de pensar dos clientes. A instituição bancária pesquisada é uma instituição privada que possui muitos anos no mercado e passou por grande modernização tecnológica, ficando muito mais eficiente e dessa forma iniciou o processo de meIhor atendimento a seus clientes. Essa instituição é uma organização voltada para os clientes. Oferece produtos e serviços financeiros especialmente projetados para o atendimento de suas necessidades. A preocupação com qualidade fica evidenciada na política de qualidade que propicia a satisfação dos clientes, funcionários, parceiros, sociedade e acionistas. Melhorar continuamente os processos, produtos e serviços, com uma equipe de profissionais qualificados e uma estrutura eficiente é meta do banco, assim como manter posição de destaque no cenário financeiro nacional e conquistar a liderança. Os valores desta instituição são: qualidade, transparência, equipe, eficiência, inovação, compromisso, solidez e foco no cliente e comprometimento com as comunidades onde opera.

A escolha do tema deu-se pela necessidade de uma conscientização acerca do que possa a vir influir a relação interpessoal no atendimento ao cliente, pois sabemos que a interação em qualquer ambiente nasce da aceitação, desprendimento e acolhimento, e no mundo atribulado em que vivemos às vezes não nos damos conta disto. Sabemos que relacionar-se é dar e receber ao mesmo tempo, é abrir-se para o novo. Pois passamos mais tempo em nosso ambiente de trabalho do que em nosso lar, e ainda assim não nos damos conta de como é importante estar em um ambiente saudável, e o quanto isto depende de cada um. Nessa pesquisa abordaram-se alguns aspectos referentes ao atendimento ao cliente, tempo de espera em filas para o atendimento nos quais a pesquisa foi realizada. 
Para este estudo foram levantadas algumas questões que consideramos importantes para alcançar os objetivos deste trabalho, são elas: As condições ambientais das empresas propiciam ou não a satisfação das necessidades básicas geradoras de motivação dos clientes? Como os ambientes físicos e sociais influem ou não as pessoas? O atendimento ofertado pelo Banco está satisfazendo a clientela das agências?

Tivemos como objetivo geral conhecer a opinião dos clientes em relação ao atendimento e as condições ambientais de uma agência bancaria na cidade de Parnaíba-PI. E como objetivos específicos: Avaliar as condições físicas e sociais do ambiente de trabalho e nas interferências nas relações interpessoais; analisar o ambiente físico-social e sua influência nos clientes; Verificar como a qualidade de vida no trabalho se reflete nas relações interpessoais; analisar as relações interpessoais dos colaboradores no ambiente de trabalho da empresa e apontar a percepção dos clientes quanto ao ambiente.

\section{METODOLOGIA}

Segundo Gonçalves, (2007, p.23), "O percurso metodológico se refere ao caminho trilhado para que você atinja os objetivos que definiu. Aqui você também deverá explicitar os instrumentos que utilizará na investigação e as fontes de pesquisa ". A pesquisa trata-se de uma pesquisa de cunho bibliográfico e de campo, onde será investigado sobre a forma de atendimento dos caixas e a opinião dos clientes na prestação de serviços oferecidos pela Agência. Este estudo é da natureza exploratória com delineamento de estudo de caso.

A metodologia utilizada é uma pesquisa de opiniões de clientes relacionada ao atendimento de caixa em uma agência bancária da cidade de Parnaíba-PI. Os dados foram colhidos por meio de entrevista semiestruturada de clientes abordados na agência, após autorização dos mesmos. As amostras foram realizadas com dez entrevistas por dia, em um período de uma semana com resultado de cinquenta entrevistas de opiniões. O número médio de pessoas que frequentam a agência é de setenta (150) por dia.

A pesquisa de campo teve a duração de pouco mais de dois meses e ocorreu nos meses de agosto e setembro de 2018. Foram pesquisados clientes que se encontravam nas filas da agência para atendimento nos caixas e avaliar potencialidade de crescimento na qualidade do atendimento. Os dados foram classificados em categorias, elaboradas por meio da revisão da literatura e respostas dadas. Os dados foram analisados também por perfil de amostra.

\section{FUNDAMENTAÇÃO TEÓRICA}

\subsection{Um breve histórico da administração}

A partir do século XVIII, com o advento da revolução industrial, o mundo mudou, provocando uma evolução e revolução da produção e do trabalho passando de oficinas artesanais para fábricas e transferindo o centro dos negócios da agricultura para a indústria. Em 1903, Taylor escreveu o primeiro livro sobre administração, lançando a teoria administrativa (CHIAVENATO, 2000).

Conforme Chiavenato (2000 p.39) os princípios da administração científica proposto por Taylor são:

O Princípio do Planejamento, que é de responsabilidade da gerência e não do trabalhador. Este é responsável apenas pela execução da tarefa. O Princípio do Preparo com seleção do pessoal para treinamento, com o intuito de produzirem mais e melhor. O Princípio do Controle, que verifica as ocorrências que se afastam dos padrões para corrigi-las adequadamente. O Princípio da Execução, que distribui distin- 
tamente as atribuições e as responsabilidades para que a execução do trabalho seja a mais disciplinada possível.

Já para Fayol os princípios são: divisão do trabalho, autoridade, disciplina, unidade de comando, unidade de direção, subordinação dos interesses individuais aos gerais, remuneração, centralização, cadeia escalar, ordem, equidade, estabelecimento na permanência do pessoal, iniciativa e espírito de equipe.

Outro ponto principal da Administração estabelecido por Max Weber (1864-1920) considerou a burocracia como máquina completamente impessoal, que funciona de acordo com as regras, enquanto as pessoas ficam em plano secundário ou nem tão consideradas. Ele estudou o alicerce formal-legal em que as organizações reais se assentam, focalizando sua atenção no processo de autoridade-obediência, que, no caso das organizações modernas, depende de leis. As principais características das organizações burocráticas, segundo Weber, agrupam-se em três categorias: Formalidade - as burocracias são essencialmente sistemas de normas. A figura da autoridade é definida pela lei, que tem como objetivo a racionalidade da coerência entre meios e fins. Impessoalidade - os seguidores obedecem à lei. As figuras da autoridade são obedecidas porque representam a lei. Profissionalismo - as burocracias são formadas por funcionários. $O$ trabalho realiza-se por meio de funcionários que ocupam cargos

Em síntese a teoria clássica foi substituída pela teoria neoclássica, a teoria da burocracia pela estruturalista e a teoria das relações humanas pela teoria comportamental. Ao mesmo tempo, surge a Teoria de Sistemas e a Teoria de Contingência, para explicar a administração nos novos tempos.

\subsection{A era da Informação}

O início da década de 1990 marca a era da informação. Ela surge com o impacto provocado pelo desenvolvimento tecnológico e com a chamada tecnologia da informação (TI), que substitui o capital financeiro pelo capital intelectual.

Conforme Maximiano, (2000 p.43). A tecnologia da informação está presente em todos os processos administrativos e produtivos, pois facilita a tomada de decisão e o desempenho de todas as tarefas de comunicação, diminui algumas funções de controle que os gerentes realizam pessoalmente, absorvidas pelos computadores, porém pode causar desemprego.

A tecnologia da informação (TI) privilegiou a união do computador com a televisão e as telecomunicações, invadindo a vida das organizações e das pessoas e agregando novas características, como: Menor espaço, Menor tempo e Maior contato. Para Chiavenato (2000 p.34) "Menor espaço: a era da informação trouxe o conceito de escritório virtual, arquivos eletrônicos acabaram com a papelada e com a necessidade de móveis associados, surgiram salas com microcomputadores, dispensando prédios e reduzindo despesas fixas. Menor tempo: as comunicações tornaram-se móveis, flexíveis, rápidas, diretas, o que permitiu maior tempo de dedicação ao cliente. Maior contato: com o microcomputador portátil, a multimídia, o trabalho em grupo, surgiu o teletrabaIho, com o qual as pessoas trabalham juntas, embora distantes fisicamente"

A TI constituiu um poderoso instrumento de trabalho dentro das organizações, por meio da Internet e da Intranet. A globalização da economia é uma das consequências dessa globalização da informação. Nessa nova era quanto mais poderosa a tecnologia da informação, mais informado e poderoso se torna o seu usuário, seja ele uma pessoa, uma organização 
ou um país. Com a informação instantânea, a mudança é muito rápida. As mudanças que estão ocorrendo nesta Era afetam profundamente as empresas do ponto de vista estrutural, cultural e comportamental, transformando poderosamente o papel das pessoas que nelas trabalham, dando ênfase na produtividade, qualidade, competitividade, cliente e globalização.

\subsection{0 funcionamento sistemático e estratégico do Banco}

A missão da área de responsabilidade social corporativa é criar e desenvolver instrumentos, projetos e programas com os quais o banco possa contribuir para o desenvolvimento socioeconômico e ambiental, favorecendo a melhoria da qualidade de vida da comunidade onde atua e da sociedade como um todo. Neste contexto, em que as palavras chave são produtividade, qualidade e competitividade, estuda-se o atendimento oferecido aos clientes pela instituição bancária na cidade de Parnaíba-PI.

A instituição financeira dispõe de projeto de nome DOIS PONTO ZERO (2.0) Em resumo, este projeto tem a finalidade de mudanças estratégicas as principais novidades advindas do projeto são: - Mudanças no encarteiramento, com a nova segmentação do "Grupo Comercial”, Pessoa Física e Pessoa Jurídica, além da criação de carteiras específicas voltadas ao Agronegócio; - Revisão da sistemática Gestão de Desempenho Profissional - GDP; - Implantação de um plano de capacitação (com cursos autoinstrucionais) voltado aos vigilantes e telefonistas, com vistas à melhoria na qualidade de atendimento ao cliente em seu primeiro contato com o Banco; - Revisão das dotações e dos cargos comissionados das agências referente ao 0800, disponibilizados para os cliente do banco: Serviço de Atendimento ao Consumidor - SAC -0800.

O banco empenha-se em fazer com que os fun- cionários possam atender seus clientes com cordialidade, simpatia, rapidez, chamando-os pelo nome, resolvendo os problemas, oferecendo os produtos do banco com presteza e buscando a fidelidade utilizando o Marketing de Relacionamento.

Esta instituição investe na aparência visual e em tecnologia, que conta com um sistema que possibilita ao cliente acessar o banco em qualquer parte do mundo. Nesse sistema, o banco tem disponível o cadastro de todos os clientes, para poder atendê-los onde estiverem 24 horas por dia. Atende também por telefone Central de atendimento do Banco do Brasil ( $C A B B)$ é um canal de relacionamento por meio do qual os clientes poderão acessar sua conta corrente e consultar saldos, extratos, cartões, efetuar pagamentos, transferências, resgates e outras transações bancárias, com segurança e comodidade, pela Internet, disponibilizando aos seus clientes software para ser instalado no computador que permite gerenciar todas as transações sem sair de casa.

\subsection{A definição de cliente}

O cliente conveniente, que não tem interesse em ir buscar o serviço (a conveniência é o segredo para atraí-lo). Clientes convenientes frequentemente se dispõem a pagar mais por serviços personalizados ou sem transtornos; por exemplo, supermercados com entrega em domicílio pode satisfazer esses consumidores.

Os clientes podem ser chamados de usuários, consumidores contribuintes ou, ainda, patrocinadores. Servir aos clientes tornou-se, na atualidade, a mais importante tarefa na organização. Segundo a literatura de Lobos (1993), clientes internos são todos os setores, grupos de trabalho e indivíduos que integram a organização e fornecem serviços a terceiros dentro dela, agregando valor a algo que está a caminho do cliente externo. E clientes externos são os que adqui- 
rem os produtos/serviços, na sua versão final.

De acordo com Uhlmann (1997), o cliente de hoje está muito mais exigente e consciente, normalmente já está decidido e sabe exatamente o que deseja. Se por acaso não souber o que deseja, sabe, pelo menos e de maneira muito explícita, o que não deseja e a maneira que não quer ser tratado. É necessário que a empresa saiba quem são os clientes internos e externos, entendê-los, satisfazer suas necessidades e comunicar seus valores além da sua missão, mantendo relacionamento positivo para a satisfação dos mesmos. A identificação dos clientes de forma ativa é muito importante para entender as circunstâncias, problemas e analisar informações, a fim de conquistar possibilidades.

É necessário que as empresas saibam tomar medidas para o atendimento, satisfazer rapidamente as necessidades e solucionar os problemas, evitando assumir compromissos que não possam cumprir. Estabelecendo feedback, põem em prática as formas de supervisionar e valorizar as preocupações, problemas e grau de satisfação dos clientes e prever suas necessidades. Em uma organização, o importante é manter o espírito de equipe e a mente aberta, reconhecer que os melhores resultados são alcançados quando trabalhamos juntos por um objetivo comum.

O empregado participa ativamente e facilitara efetividade da equipe, atua demonstrando consideração pelos sentimentos e as necessidades do grupo. Cada equipe, sendo totalmente responsável por sua própria produtividade, qualidade e segurança no trabalho, proporcionará um bom resultado.

Segundo Uhlmann (1997, p.198-199), "o perfil do cliente tem se alterado ao longo dos anos de acordo com a evolução tecnológica, exigindo maior qualidade e aprimoramento por parte dos seus fornecedores". A empresa deverá estar sempre evoluindo e se adaptando ao que o mercado oferece, nos cam- pos administrativo e tecnológico e, principalmente, ao que o cliente necessita.

Um dos pontos fundamentais é que o cliente satisfeito não é somente um cliente para sempre, mas sim um cliente que ajuda a "vender" a imagem da empresa para outros clientes. Um cliente insatisfeito é um cliente perdido e dificilmente será recuperado e, com isso, vende a imagem negativa da empresa para outros possíveis clientes em potencial. A qualidade em serviços tem a ver com satisfação das expectativas dos clientes.

\subsection{0 que o cliente espera da empresa}

Como podemos saber os desejos dos clientes? A resposta é questioná-los e ouvir sua voz. Essa técnica permite identificar o grau de satisfação, a partir da manifestação voluntária dos mesmos, quer seja por meio de centrais de atendimento quer por contato direto do pessoal de frente.

Estar sempre próximo do cliente seja na comunidade, seja no mercado ou, principalmente, no dia a dia, garante a manutenção de um canal direto e rápido para a coleta de informações sobre a satisfação e resulta em aumento de lucros. Assim, o cliente e sua fidelidade passam a ser o principal foco das empresas, que buscam vantagem competitiva tendo como base a qualidade Lobos (1993 p.102-103) relaciona algumas opiniões do tomador de serviços, que julga serem fundamentais: $O$ que o Cliente espera do serviço oferecido; que importância confere ao que espera do serviço; Dentro do que espera, o conhecimento que tem do máximo que o mercado oferece; $\mathrm{O}$ que se pode fazer pelo cliente "aqui e agora". As instituições públicas e privadas publicam periodicamente os resultados de suas pesquisas.

A melhor pesquisa é aquela realizada pelo pessoal que atende diretamente os clientes no dia-a-dia para identificar por que o cliente reclama. Na verda- 
de, eles reclamam quando têm seus direitos desrespeitados, pois as pessoas estão mais conscientes da legislação que as protege e estão valorizando cada vez mais o seu dinheiro, exigindo o cumprimento do prometido pelos seus prestadores de serviços. A entrevista é uma outra técnica utilizada por meio de contato pessoal ou telefônico, pode ser individual ou em grupos, possibilitando críticas ou sugestões sobre um determinado produto ou serviço.

As reclamações do consumidor são essenciais para que as correções sejam feitas e dois tipos podem ocorrer: os consumidores podem não reclamar ou as reclamações podem ficar retidas e nunca atingirem a empresa ou o processo que causou o problema.

Campos (1999 p.123) confere o tratamento das reclamações e reivindicações à condição de grande prioridade de uma empresa. Aconselha montar um "padrão de sistema" com base em um fluxograma do processo de tratamento das reclamações e reivindicações, com o treinamento de todo o pessoal envolvido. Sugere uma análise de Pareto (método que ajuda o gerente a classificar e priorizar os seus problemas) dos casos de reclamações e reivindicações dos últimos meses com itens de controle (número de reivindicações $x$ tempo e número de reclamações $x$ tempo), definindo os projetos prioritários e atribuindo responsabilidade pela solução dos problemas às várias áreas funcionais da empresa, e aconselha que deva ser repetido continuamente até que possa eliminar as reclamações e reivindicações.

Portanto, é necessário que haja um marketing de relacionamento, que se trata de processo contínuo de criação, compartilhamento de valores com os clientes, reconhecimento da importância de aprender com os clientes, pois os relacionamentos são os únicos bens verdadeiros da empresa, a oportunidade de aumentar tanto o rendimento quanto ao lucro de diversas maneiras. Os funcionários são reconhecidos pela prestação de serviços de qualidade e deverão saber que serão responsáveis pelos padrões pelos quais seu desempenho será medido. Para atingir qualidade de atendimento, é necessário treinamento contínuo dos funcionários.

A ferramenta-chave para a criação e manutenção do foco no cliente é a realização de reuniões regulares com o pessoal, incentivando-os a contribuir para a pauta de cada reunião, o que lhes permite a oportunidade de expressar suas necessidades e sentimentos. Isso melhora muito o desempenho do funcionário no atendimento

\subsection{Como atender o cliente}

O desempenho dos funcionários é um dos fatores que mais afetam no resultado de uma empresa. A venda só será bem completa se os vendedores desempenharem seu papel de acordo com a expectativa de seu cliente, e, para conseguir bons negócios, é essencial a participação de todos os funcionários desde o porteiro até a gerência e alta direção.

Já os profissionais de marketing repercutem a voz do cliente não apenas dentro da estratégia de negócio, mas sim dentro do planejamento de processo, adoção de tecnologia, fatores pessoais e criação e administração de conhecimento (LOBOS, 1993 p.103).

No setor bancário, o atendimento personalizado é muito importante e o funcionário precisa saber querer e atender bem seus clientes, pois a concorrência é muito grande e, tendo motivação, consegue um resultado positivo. As oportunidades perdidas criam problemas para as organizações, e os problemas, entretanto, podem ser transformados em oportunidades. Podemos conquistar fidelidade no momento da solução de problemas, na venda de um produto, oferecendo bom atendimento e suprindo as necessidades dos clientes.

De maneira geral os empregados que têm tarefas 
de responsabilidade são mais motivados e satisfeitos com os cargos que possuem, pois eles são envolvidos com altos níveis de variedade de habilidades e atividades, tornando-se mais comprometidos e capazes de responder pelos seus atos.

O feedback dá uma compreensão útil de seus papéis e de suas funções específicas. À medida que o trabalho se tornar mais desafiador e que aumentar a responsabilidade do empregado, sua motivação e seu entusiasmo deverão crescer. Porém, é muito difícil motivar todos de uma só maneira, pois as pessoas são diferentes, pensam diferentes. É importante que todos os funcionários cheguem a um acordo, satisfazendo a necessidade de realização.

As expectativas, resultados e comportamento no trabalho diferenciam em cada funcionário, já que o comportamento é determinado por uma combinação de fatores do próprio indivíduo e do ambiente, o que torna as necessidades, desejos e objetivos também diferentes. $\mathrm{O}$ administrador deve possibilitar que os subordinados se sintam úteis e importantes, reconhecidos como indivíduos. Os funcionários devem esta motivados, seja na solução dos problemas das empresas, seja na promoção da integração e da confiança entre os participantes da organização (CHIAVENATO, 2000).

Para Uhlmann (1997, p.44) a primeira visão da motivação são, Teoria Comportamental nos trabalhos de Abraham Maslow e F. Hezberg ampliou e complementou de maneira científica essa visão inicial, foi a de que as pessoas são compelidas a agir com as necessidades que são classificadas em: a) necessidades fisiológicas, que são ligadas à sobrevivência, tais como alimentação, abrigo, proteção; b) necessidades psicológicas, que se constituem de fatores como a segurança, a participação em grupos, a autoconfiança e a afeição; c) necessidades de autorrealização, que se referem ao potencial de cada um.

\section{RESULTADOS DA PESQUISA}

As tabelas abaixo mostram os resultados da pesquisa efetuada com os clientes no $5^{\circ}$ dia útil e nos dias $10-11-12-13-14$ do mês de setembro de 2018, na Agência. Foram elaboradas por critérios de faixa etária e gênero.

Tabela 1: Resultados da pesquisa dos clientes entre 17 a 40 anos do sexo masculino.

\begin{tabular}{|c|c|c|c|c|c|c|c|c|c|c|c|}
\hline \multicolumn{2}{|c|}{ ESCOLARIDADE } & \multicolumn{3}{|c|}{ CAIXA } & \multicolumn{3}{|c|}{ CENTRAL DE ATENDIMENTO } & \multicolumn{3}{|c|}{ GERENCIA } & \multirow{2}{*}{ Media } \\
\hline $2^{\circ} \mathrm{Grau}$ & $3^{\circ} \mathrm{Grau}$ & Ótimo & Bom & Regular & Ótimo & Bom & Regular & Ótimo & Bom & Regular & \\
\hline 6 & 5 & 5 & 5 & 1 & 2 & 8 & 1 & 2 & 5 & 4 & 8,5 \\
\hline
\end{tabular}

Fonte: Pesquisa realizada com clientes na Agência no período de maio a setembro de 2018 
Observa-se que, na faixa etária entre dezessete e quarenta anos, sexo masculino, seis possuem segundo grau completo e cinco têm nível superior. Cinco dessa população consideraram que o serviço de atendimento no setor "caixa" está regular. Eles que- rem ser atendidos rapidamente e reclamam da falta de mais funcionários para o atendimento de caixa. É preciso ter mudança. A diferença é que as clientes do sexo feminino adoram ser atendidas pelos caixas com cordialidade e saudação.

Tabela 2: Resultados da pesquisa dos clientes entre 41 a 60 anos do sexo masculino

\begin{tabular}{|c|c|c|c|c|c|c|c|c|c|c|c|}
\hline \multicolumn{2}{|c|}{ ESCOLARIDADE } & \multicolumn{3}{|c|}{ CAIXA } & \multicolumn{3}{|c|}{ CENTRAL DE ATENDIMENTO } & \multicolumn{3}{|c|}{ GERENCIA } & \multirow{2}{*}{ Media } \\
\hline $2^{\circ} \mathrm{Grau}$ & $3^{\circ} \mathrm{Grau}$ & Ótimo & Bom & Regular & Ótimo & Bom & Regular & Ótimo & Bom & Regular & \\
\hline 1 & 6 & 7 & 0 & 0 & 6 & 1 & 0 & 2 & 4 & 1 & 9 \\
\hline
\end{tabular}

Fonte: Pesquisa realizada com clientes na Agência no período de maio a setembro de 2018

Observa-se que, na faixa etária entre quarenta e sessenta anos, sexo masculino (todos com o segundo grau completo), nove dos clientes consideraram ótimo o serviço de atendimento dos funcionários no setor "caixa"; cinco o consideraram ótimo no setor "central de atendimento"; e quatro, na gerência.

Tomando como base Las Casas (1999), que prioriza pesquisas com os clientes a fim de conhecer suas expectativas, Lobos (1993), que sugere um planejamento para o atendimento aos clientes, e Campos (1999), que procura manter um estreito relacionamento com o cliente para tratamento de suas reclamações e reivindicações, elaborou-se uma pesquisa com os clientes da instituição bancária na cidade de Parnaíba-PI, para identificar as opiniões dos mesmos quanto à forma como estão sendo atendidos pelos funcionários da agência de Taubaté. Foram elaboradas as seguintes perguntas e direcionadas aos clientes na hora do atendimento;
1. O que o Senhor (a) acha do atendimento do banco No caixa:

( )REGULAR ( ) BOM ( ) ÓTIMO

2. O Senhor (a) acha que deveria haver uma mudança? O quê e Por que? SIM ( ) NÃO ( )

3. Dê uma nota para o atendimento: ( )1( )2( )3( )4( )5( )6( )7( )8( )9( )10

4. O senhor (a) costuma a demorar muito na fila do caixa: SIM ( ) NÃO ( )

5. O tempo que o Senhor (a) aguardou para ser atendido foi adequado? SIM ( ) NÃO ( )

6. Cumprimentaram o Senhor (a) com bom dia ou boa tarde? SIM（） NÃO（）

7. O Senhor (a) foi atendido com um sorriso? $\operatorname{SIM（）NÃO（）~}$

8. Agradeceram sua vinda ao banco?

$\operatorname{SIM}(\quad)$ NÃO ( )

9. Chamaram o Senhor (a) pelo seu nome? $\operatorname{SIM}(\quad) \mathrm{NÃO}(\quad)$

10. O funcionário que o atendeu resolveu seu problema? SIM ( ) NÃO ( )

11. Foi oferecido algum produto ou serviço do banco?

$\operatorname{SIM}(\quad) \quad$ NÃO ( ) 
Através destas questões foi possível analisar em percentuais os clientes contentes e satisfeitos com o atendimento feito pelos caixas na agência e o potencial que a Agência disponibiliza para um melhor atendimento e para comprovar e mostra o percentual pesquisado mostraremos em gráficos a seguir.

Gráfico 01: Analise do atendimento ao cliente

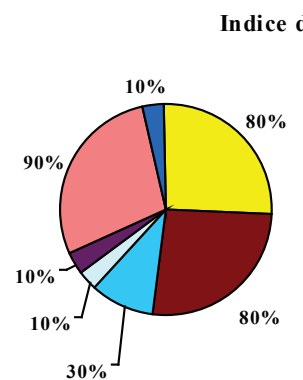

$$
\begin{aligned}
& \square \text { TEMPO DE ESPERA ADEQUADO } \\
& \square \text { FORAM CUMPRIMENTADAS } \\
& \square \text { FORAM ATENDIDAS C/ SORRISO } \\
& \square \text { AGRADECIDAS PELA PREFER. } \\
& \square \text { FORAM CHAMADAS PELO NOME } \\
& \square \text { PROB LEMAS SOLUCIONADOS } \\
& \square \text { OFERECERAM SERV. BANCARIO }
\end{aligned}
$$

Fonte: Pesquisa realizada com clientes na Agência no período de maio a setembro de 2018

As respostas foram muito variadas: $80 \%$ dessas pessoas responderam que o tempo de espera foi adequado e foram cumprimentados; $30 \%$ foram atendidas com sorriso; $10 \%$ foram agradecidos pela vinda ao banco; $10 \%$ foram chamados pelo nome; $90 \%$ tiveram seus problemas solucionados; e $10 \%$ dos entrevistados foram oferecidos produtos do banco, tais como abertura de contas correntes, cartões de créditos, e título de capitalização, previdência privada.

Gráfico 02: Notas da qualidade no atendimento ao cliente dos caixas na Agência de Parnaíba-PI

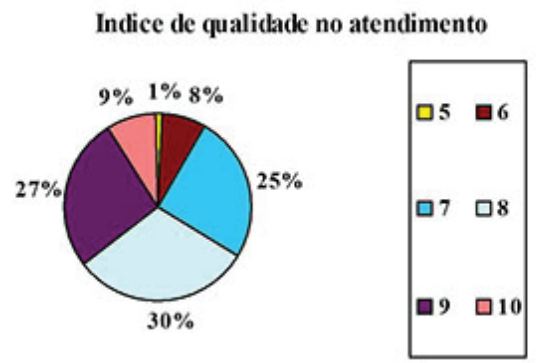

Fonte: Pesquisa realizada com clientes na Agência no período de maio a setembro de 2018
As notas dadas pelos clientes aos funcionários da instituição foram: $1 \%$, nota $5 ; 8 \%$, nota $6 ; 25 \%$, nota $7 ; 30 \%$, nota $8 ; 27 \%$, nota 9 ; e $9 \%$, nota 10 .

Gráfico 3: Análise do tempo em espera para atendimento em fila nos caixas da Agência de Parnaíba-PI

Indice de tempo no atendimento

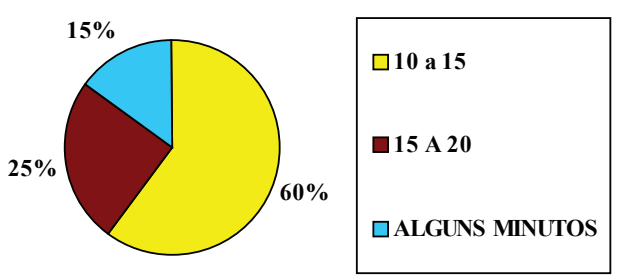

Fonte: Pesquisa realizada com clientes na Agência no período de maio a setembro de 2018

O tempo máximo que os clientes aguardaram para serem atendidos no caixa foi aproximadamente de 10 a 15 minutos $60 \%$, em alguns minutos $15 \%$, e de 15 a 20 minutos $25 \%$. Para que este projeto seja eficiente e tenha resultados positivos e constantes, o gerente geral convoca reuniões duas vezes semanalmente com todos os funcionários, que são 7 , para que se revezem na contribuição dos serviços da bateria de caixa, todos empenhados em agilizar o atendimento para que se consiga o resultado esperado.

Gráfico 04: Índice de qualidade no atendimento dos caixas na Agência de Parnaíba-PI nos dias de pagamento INSS, Estado e Município.

Indice de qualidade no atendimento

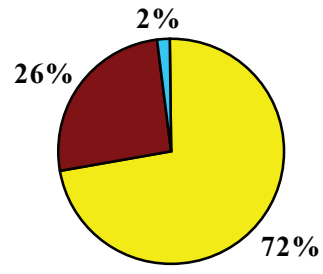


Em setembro de 2010, a partir do quinto dia útil, foram entrevistados 25 clientes, dos quais $72 \%$ disseram que o atendimento dos caixas está ótimo, $26 \%$ acham que o atendimento melhorou muito, e $2 \%$ sugeriram mais caixas para o dia do pagamento, pois é o dia que todos querem pagar suas contas ou retirar seu dinheiro e solicitaram também água para tomarem enquanto esperam. Foi observada a dificuldade que os clientes encontram em subir ao primeiro andar para o atendimento dos caixas e sugere que 0 banco desça o setor dos caixas para o térreo e que a televisão esteja sintonizada em jornais e não em desenhos animados, como na atualidade.

$\mathrm{O}$ atendimento feito com número "senha" tem boa receptividade, porém a identificação do caixa deveria estar mais visível, na altura dos olhos, e não ao lado do caixa, pois dessa forma os "displays" atrapalham a visão. Na fila preferencial, foi solicitado um atendimento rápido, sem uso de senha. O cliente deve chegar ao banco e ser atendido imediatamente, quando o caixa terminar de atender o cliente com senha em andamento. Com relação ao setor gerência, foi enfatizada a ausência do gerente. Um cliente disse que, todas as vezes que vem a agência, o gerente sempre está ausente.

Os clientes necessitam de empréstimos e reclamam dos juros altos e não conseguem negociar com o gerente. Na central de atendimento, a reclamação é de que o serviço é muito demorado, de que as estagiárias não conseguem esclarecer as dúvidas dos clientes e de que faltam funcionários no setor. A administração científica determina um método de trabaIho para maximizar a eficiência, analisando a melhor maneira para obter bons resultados.

Com a tecnologia da informação, os clientes são atendidos em menor tempo, possibilitando maior contato por telefone e Internet, utilizando menos espaço e obtendo bons resultados para o Banco. A par- tir dessas informações, os gerentes de atendimento devem fazer uma análise e elaborar planos de ação operacional, de forma a dar respostas rápidas para os clientes.

O banco oferece cursos de treinamento para todos os funcionários sobre atendimento rápido e cordial para os clientes e não clientes. E, para que isso aconteça, é preciso a colaboração de todos os funcionários envolvidos, desde o porteiro até a alta gerência, e, preferivelmente, todos eles devem conhecer todos os assuntos relacionados à empresa. Se for necessário, deve-se proceder à contratação de mais funcionários.

\section{CONCLUSÃO}

Já com as pesquisas efetuadas com os clientes, constatou-se a necessidade de mudanças no tratamento com os clientes e uma nova postura dos funcionários, buscando ser mais cordiais, competentes e que procurassem resolver problemas, dentro das Instruções Normativas-IN, determinada pelo Banco.

Para acompanhar as rápidas e complexas mudanças pelos quais o mercado de trabalho está passando, é preciso buscar atualização constante em tecnologia, comportamento organizacional e relações humanas. Conseguindo dominar as dimensões acima, as empresas podem acompanhar o ritmo das mudanças, dos desejos e das necessidades dos seus clientes. Investir em capacitação técnica e relacionamento interpessoal é fundamental para que os funcionários consigam resolver os problemas, identificar, analisar e planejar o atendimento das necessidades dos clientes, pois a competição entre os bancos é acirrada.

Em qualquer fase do processo, sempre existirão novas necessidades e novos problemas para resolver, novas oportunidades e capacitação das pessoas e equipes e isso quer dizer que a busca pela melho- 
ria contínua não tem fim. Neste trabalho, procurou-se identificar a opinião dos clientes sobre o atendimento dos funcionários do banco, na agência de Parnaíba-PI e refletir, com base na revisão da literatura, sobre os comportamentos mais adequados para satisfazer os clientes e obter resultados operacionais positivos.

Observa-se que o resultado obtido na pesquisa contribui de forma concreta, tanto para melhorar o atendimento dispensado pelos funcionários aos clientes, quanto para valorizar as opiniões dos clientes em relação aos serviços da instituição. Dos 25 clientes entrevistados neste trabalho, a maioria está satisfeita com as mudanças já efetivadas pela agência em referência, tais como; visual agilidade e cortesia no atendimento, entre outras.

Todavia, há ainda os insatisfeitos, que demonstram seu desagrado dando sugestões e fazendo críticas. Durante a pesquisa, foi constatado que, embora a instituição tenha se prontificado a fazer alterações de acordo com as sugestões dadas pelos entrevistados, é uma tarefa muito difícil satisfazer a todos os clientes, haja vista suas diferenças individuais, ou seja, o que é positivo ou bom para alguns não é para outros.

Há pessoas que gostam de mudanças, do novo, do desconhecido; já outras são mais acomodadas, conservadoras, preferindo permanecer no que é familiar a eles. Com a mudança do perfil do cliente, principalmente na questão da tecnologia, eles se tornaram mais exigentes, no momento da compra do produto ou uso de serviços prestados. Isso tem demandado maior empenho das empresas no momento de vender ou de prestar serviços.

Os resultados desta pesquisa solidificaram a afirmação acima, pois mostrou que a maioria dos clientes é exigente e sabe o que quer. Considerando-se os resultados desta pesquisa e literatura sobre o assunto, sugere-se, para trabalhos futuros, constante monitoramento do nível de satisfação do cliente, com objetivo de acompanhar as eventuais mudanças em seu perfil, decorrentes do avanço da tecnologia, por exemplo, e adequar-se a elas. 
Terceiro Setor

\& Gestão
UM ESTUDO DE CASO SOBRE A OPINIÃO DOS CLIENTES EM RELAÇÃO AO ATENDIMENTO E AS CONDIÇÕES AMBIENTAIS DE UMA AGÊNCIA BANCARIA NA CIDADE DE PARNAIBA-PI Edson Medeiros Rodrigues Netto

\section{REFERÊNCIAS}

CAMPOS, Vicente Falconi. TQC Controle da Qualidade Total (No Estilo Japonês). 8.ed. Belo Horizonte: EDG,1999. 224p.

CHIAVENATO, Idalberto. Administração nos Novos Tempos. 6.ed. Rio de Janeiro: Campus, 2000.710p.

DESATNICK, Roberto L. \& DETZEL, Denis H. Gerenciar Bem é Manter o Cliente.I ed. São Paulo: Pioneira, 1994. 237p. (Câmara Brasileira do Livro, SP, Brasil).

GALE, Bradley T. Gerenciando o Valor do Cliente. 1. ed. São Paulo: Pioneira, 1996. 368p. (Câmara Brasileira do Livro, Sp, Brasil).

GONSALVES, Elisa Pereira. Conversas sobre iniciação à pesquisa científica. 4.ed. Campinas: Alínea, 2007.

KOTLER, Philip. Administração de Marketing. 10.ed. São Paulo: Prentice Hall, 2002. 764p.
LAKATOS, Eva Maria; MARCONI, Marina de. Fundamentos de metologia científico. 6.ed. 5. reimp. São Paulo: Atlas,2007

LAS CASAS, ALEXANDRE L. Qualidade Total em Serviços. 3.ed. São Paulo.Atlas, 1999. 206p.

LOBOS, Julio. Encantando o Cliente Externo e Interno. São Paulo: Instituto da Qualidade, 1993, 270p.

MAXIMIANO Antonio César A. Teoria Geral da Administração. 3.ed. São Paulo: Atlas, 2000, 530p. PÁDUA, Elisabete Matallo Marchesini de. Metodologia da pesquisa: abordagem teóricas práticas. Campinas, SP: Papirus, 2000.

STONER, James A.F.; FREEMAN R. Edward. Administração. Rio de Janeiro: JC.1999. 533p.

UHLMANN, Günther W. Administração Das Teorias Administrativas à Administração Aplicada e Contemporânea. São Paulo FTD, 1997. 214p. 